\title{
Transition Program: The Challenges Faced by Special Needs Students in Gaining Work Experience
}

\author{
Aliza Alias ${ }^{1}$ \\ ${ }^{1}$ Faculty of Education, Universiti Kebangsaan Malaysia, Malaysia \\ Correspondence: Aliza Alias, Faculty of Education, Universiti Kebangsaan Malaysia, 43600 UKM Bangi, \\ Selangor, Malaysia. Tel: 603-8921-6273. E-mail: eliza@ukm.edu.my
}

Received: July 22, 2014 Accepted: November 5, 2014 Online Published: December 21, 2014

doi:10.5539/ies.v7n13p192 URL: http://dx.doi.org/10.5539/ies.v7n13p192

\begin{abstract}
Transition program for special needs students is known to open opportunities for students with learning disabilities to gain work experience in actual work environment. The program provides training activities and also an opportunity to go for internship to gain work experience. Therefore, this study is to identify the challenges faced by special needs students in gaining work experiences during their internships. Two students were selected and trained to acquire work-related skills as preparation for their internships. Findings from this study revealed that, at the beginning of the internships, both of the students have to overcome several challenges, working in their respective work places. The students were having problem in adjusting to their new work environment, interacting with co-workers, understanding instructions and also displaying negative attitudes. Fortunately with the assistance from special education teachers, supervisors and co-workers, both special needs students have proven that they were able to gain valuable work experience at the end of their transition program.
\end{abstract}

Keywords: special needs students, transition program, work experience, work environment

\section{Introduction}

Getting a job for a person with learning disabilities is an issue as employers have the tendency not to employ those who have special needs. They are not always given the opportunities to gain work experience and maximize their potential in the working world. Even though some of them have basic learning skills and capable to acquire vocational skills through training (Aliza, 2013), but according to Lindstrom, Doren, and Miesch (2011) employment opportunities for those with special needs are very limited as work experience is stated as one of the criteria in job application. Furthermore, the importance of work experience was stressed by Oertle and Trach (2007) as one of the components to develop minimum qualification for employments beside training and education. Butcher and Milton (2008) also agreed that experience would be an asset in searching for employment.

Therefore, opportunities to gain work experience in actual work environment should be given to those who have learning disabilities, so that they would be able to get jobs and earn a living on their own. Lindstrom et al. (2011) stated that, it was important for special needs young adults to gain work experience. Not only it helped them to gain work experience but also critical work skills and relevant work related behaviors. They also added that work experience were primarily positive, allowing the students to gain additional opportunities and skills needed for the related task/job.

According to Aliza (2013) the objectives of transition program from school to work environment were to train special needs students to acquire relevant skills and gain work experiences outside their learning environment. As the placements at actual work places with general work skills needed would give them the opportunities to learn about teamwork, responsibilities, and work ethics (Lindstrom et al., 2011). Therefore, the transition programs were planned accordingly to the students' capabilities so that they could continue the learning process at their work place. Moreover, Shogren and Plotner (2012) defined transition program as a coordinated set of activities that is designed for specific students with learning disabilities that promotes the students' transition to work place after being trained the required work skills. This program is not only to train the students the work-related skills but also to prepare the students with relevant skills needed to function in the work environment. After they have acquired the skills, the students would be placed in the work place for a period of time. These experiences would assist them to be independent after leaving school life. Thus, the work experience 
gained through transition program would lead to the opportunities to work after leaving school, and indirectly would also boost up the students' self-confidence to enter work force in the future (Lindstrom et al., 2011).

The transition programs in Malaysia were implemented by special education teachers. The teachers would carefully select qualified students with learning disabilities to be trained in the program. These students' academic skills were not only assessed by the teachers but also their social and emotional development. Therefore, several observations were done in the class and also outside the class to identify their abilities in coping with the demands of the work environment later. The data gathered would provide information in planning learning activities in the transition program. The transition programs' activities are designed based on the students' needs, interests, and also their goals to be in the program. The students were taught and prepared about career-related learning and the need to gain work experience. The transition program also provided specific learning process and assistance in preparing the future interns to function in the actual work environment. The teachers also the students' knowledge and skills especially in coping with the needs and demands at the work place including communication and social skills. This was to initiate positive interaction with co-workers or supervisor and ultimately build good relationships for the students' well-being in the work environment. It was not an easy task for the teachers to look for employers that would accept these trained students as interns at their premises, as most of the employers approached by the teachers were reluctant to accept an intern with learning disabilities. However, with the teachers' determination to prove that these students were capable to work, finally a place of internship for these special needs students to gain work experience was secured (Aliza, 2013). Even though the students are trained and prepared to work but the success of the transition program depends on how the students adapt into their working environment. These trainee are bound to face challenges with their limited communication and social skills, in addition to their behavior and attitudes issues that would interfere with the process of gaining work experience. Therefore this study's objective is to identify the challenges faced by students with learning disabilities during their internships in the real work environment.

\section{Method}

This case study explores the challenges faced by the trainees during their internships at respective work environment. These students were selected by their special education teachers after several observations done at their schools, to identify their communication skills and their coping ability to adapt socially and emotionally in new environment. Both students have very limited basic academic skills and were also assessed on their capability in basic learning skills and the ability to be trained in the transition program. The teachers also focused on the personalities and behavior which were important elements to ensure that the students were able to adapt and complete the internship at work environment. Both of the students have learning disabilities and other difficulties such as social skills and behavior issues. The two students were trained specifically on the work-related skills needed for their transition program from school to work places. Apart from learning and acquiring the work skills needed, the students were also prepared for the social and emotional demands that they would face while going through their internships. The students were also taught the rules, regulations procedures that the students should be aware of once they started working at their respective work places.

The first student (student A) was a 17 year-old student, who was trained to wash cars and placed at a car wash center. He was a quiet boy and always felt comfortable on his own. He also seldom interacts with peers as he stuttered every time he wanted to speak. This student has very limited basic learning skills as he faced difficulties in reading even simple words. On the other hand, Student B (16 year-old boy) was trained to work at a minimarket as an assistant. Even though he enjoyed working but sometimes he had emotional and social issues. He has basic learning skills but he a fast learner with new skills taught at the minimarket.

After two weeks of training at school, the students started their internships for 6 weeks at their respective work environment. The supervisor and co-workers were briefed on the students' special needs characteristics, such as the students' personalities, behaviors, weaknesses and strengths. The teachers also informed the supervisors and co-workers on how to handle or deal with the students' misbehavior or any issues regarding emotional and social that might emerge during the internships. At the beginning of the internships, the teachers were present at the work places, helping the students to get used of the new environment. At the same time, the teachers also assisted the co-workers and the supervisors to understand the interns' learning disabilities and their abilities to function in the work environment.

Both of the students were observed by the teachers and supervisors during their internships. At the end of the internships period, the teachers, co-workers and the supervisors were interviewed on the problems and issue faced by the students in adapting to the new environment. The students also were observed on coping with emotional and social issues, and also their understanding in work ethics. 


\section{Results}

The objective of this study was to identify the challenges faced by the special needs students during their internships. The feedbacks from teachers, co-workers and supervisors were analyzed thematically and data revealed that the students have difficulties in adapting to the work environment, communicating with co-workers, understanding instructions and completing the tasks given.

\subsection{Adapting to the Work Environment}

Based on the teachers' observation and the feedbacks from the co-workers and supervisors, it was clear that the main issue faced by the students was adapting to the work environments. As leaving their comfort zone in schools to continue learning an eventually gaining work experience in real work places was a big challenge for these students. They felt insecure and uncomfortable working or rather learning in a totally different and new environment.

The teachers agreed that the students have problems in adjusting to the routine and rules or regulation at their work places. As a result, the teachers had to help the students to accept the new environment as a place to learn and gain work experience which is important for their future. At the beginning of the internships, the teachers were constantly explaining to the students why they need to be there and do the tasks given. Feedbacks from the co-workers and supervisors also showed that the interns were stressed at the beginning of their internship trying to adapt to the new work environment.

Furthermore, the need to learn and acquire new skills in completing the task given also posed a problem to the students. They were not happy with these situations as learning new things and new skills at work environment stressed them. In addition of being outside of their comfort zones, the students also felt uncomfortable meeting new people such as supervisors, co-workers and also customers during their internships. This uncomfortable situation at work place eventually caused the students to face their next big challenge that is communication.

\subsection{Communication Skills}

Both students in this study possessed low communication skills. Their interactions although limited with their co-workers, supervisors and even customers were not positive. The students were unable to function efficiently in their work environment. It is difficult for the students to gain work experience successfully if there were only minimal interaction between them and their co-workers or supervisors. As both students were very shy and have very low self-confidence, they were afraid or reluctant to interact with co-workers or their supervisors, even when they had problems while completing a task. In fact, at the beginning of the internship, student A refused to cooperate and participate in the task of washing the cars with his co-workers as he stuttered every time he wanted to say something. Therefore, the disability to communicate with co-workers and supervisor or even the customers hampered his chances in gaining work experience. It was difficult for both students to ask for help when they didn't understand what to do or didn't know what to do next after finishing the task given. With limited interactions, both of the students tended to lose focus when they failed to complete the task given efficiently.

\subsection{Difficult in Understanding Instructions}

In transition program, the students were trained only on basic work-related skills in school, as the school had limited facilities in providing the similar work environment such as car wash center or mini market. Therefore, there were a lot of new things and new skills that the students need to learn once they started their internships at their respective work places. Even though with limited facilities and accessibilities at school, the students were trained by experienced special education teachers who were also qualified in teaching special needs students. The students also felt comfortable being trained by somebody who was familiar with their characteristics and learning disabilities. On the other hand at their work place, these students were required to learn new things or new skills from their co-workers and supervisors. This situation caused them to face difficulties as they didn't understand the instructions given by their co-workers or supervisors whom they hardly knew. In addition, the environment of working in the actual work place such as mini market or car wash center was totally different from the learning environment in schools. Therefore, getting instructions from somebody who were not knowledgeable about the special characteristics and also the learning disabilities of the students would impede the process of gaining work experience. Unfortunately, failing to understand the instructions on how to execute new task forced the students to display attitude problems.

\subsection{Students' Attitudes in Completing the Task}

The process of gaining work experience also could be hampered by the students' attitudes too. This would lead to their low performance which was no acceptable by the supervisors. In this study, both of the students also 
have difficulties in following rules and procedures that were implement by the supervisors. They also felt bored with the task given as they were not interested in learning new things or having difficulties in completing the task efficiently. Sometimes they got upset when they were told to do the task correctly or they were reluctant to follow the instructions given and procedures required when executing the task. The students also completed the task given poorly or worse did not finished the task at all. For example, student B was reluctant and unhappy to receive instructions from his supervisor. As a result, he refused to do the task given as he was uncomfortable taking instructions from other than his teacher. He was also not interested to do some of the task given as he was bored with the task or have difficulties in completing the task. As both of the students lost focus easily while executing their task, they failed to complete the task efficiently. Students B also showed some constraint during his internship when he was asked to memorize the price of certain merchandise so it would be easier to serve the customer directly rather than keep asking the supervisor about it. It was a difficult task for him but with the assistance of supervisor he successfully memorized the price and was able to locate the merchandise needed on his own. On the other hand, student A couldn't keep track on the number of cars coming and going out of the center. Due to the fact that he was also couldn't write properly, the employer decided to give him the task of washing the cars only.

Even though, both students had to go through some challenges in the process of learning and gaining experience in their respective work place, but they had shown remarkable positive changes in their emotional and social development. Finally the students were able to adjust and adapt to their working environment and gave their best till the end of the internships.

\section{Discussion}

This study highlights the challenges faced by the students with learning disabilities while trying to gain work experience in the actual work environment. One of the findings indicates that at the beginning of the students' internships, they have difficulties in adapting to the new learning environment at real places which were different from their comfort zone in schools. Being uncomfortable with the new environment and new faces at work, ignited behavior and attitude problems as they were trying to make adjustment to their new found work environment. As a result, the students had to rely on their teachers who were there for the first few days of the internship to assist them in adjusting to the new environment, before they started to trust and accept their co-workers and supervisor as part of their learning mentors.

The feeling of being accepted as one of the team in their work environment helped the students to feel safe and comfortable to go through the internships with minimal attitudes problems. However, the success of the students in gaining work experience lies on the understanding and patient of the individuals who worked closely with the students in the work environment such as the co-workers and supervisors. The commitment to understand and provide the essential needs and support the students physically, socially and also emotionally were important component to build healthy work environment for the students' well-being. As Pinkney, Murray, and Lind (2012) suggested that to improve student functioning across multiple context, individual skills that are predictive of functioning across multiple domains should be focused during the training session.

Even though, the students were having difficulties adjusting to the work environment, but they were able to overcome the problems and adjusted successfully emotionally and socially that they were able to gain the work experience. But with understanding and helpful co-workers and supervisor would also help the student not only gain work experience but also raise the level of self-confidence and self-efficacy. However, the students were able to adapt to the work environment and feel comfortable to work happily with patient and caring co-workers and supervisors. Being accepted as part of the team in completing the task given, had helped the students to overcome their shyness in communicating as they successfully overcame their fear of interacting with others others, as limited interactions and low self-esteem would interfere with the students communication skills in the work environments. In addition the employers were aware of the students' needs to feel safe and be accepted in the working environment that they attended to interns' needs not only physically but also social and emotional needs at their premises.

Furthermore, individual attributes such as self-efficacy, motivation, and coping skills played a clear role in the ability to obtain and maintain living employment overtime as indicated by Lindstrom et al. (2011) would make the interns highly motivated to work and have positive interaction in the workplace. Both of the students were fortunate and highly motivated when their employers gave them some allowances after they had finished their internships. According to Butcher and Wilton (2008), most placements during transition program are part time, and wages vary with some entirely voluntary, other offer minimal training allowances and some paying around minimum wage. Even though, both students had finished their internship, but they were looking forward to 
continue working at the premises. The transition process planned should benefit the students, as the program identify desired outcomes, plan experience and acquire knowledge and skills to meet these goals. Moreover, Thomas and Dykes (2011) believed that previous experiences, the ability to crystallize and clarify their preferences and interests, and the ability to communicate preferences and interest in an age appropriate manner is sufficient to function in the real world of employment. It is essential for the students to be prepared before venturing into the working world and earn a living on their own.

\section{Conclusion}

Transition program from school to work is an opportunity for the students with learning disabilities to gain work experience. With the assistance and supports from teachers, supervisors and co-working, special needs trainees are able to overcome these challenges and complete their internships with self-confidence and pride that they are able to work given the adequate training and emotional support at work place. Though they have to face several challenges such as adapting to the new work environment, experiencing difficulties to communicate and understand instructions and also completing tasks given on time. Therefore the success of the special need students to overcome the challenges in gaining work experiences in the actual working environment not only depends on the training in schools, but also the commitment of the individuals who played important roles as mentors and friends throughout the internship period.

\section{References}

Aliza, A. (2013). The issues in implementing transition program for special needs students. Asian Social Science, 9(16), 9-14.

Baxter, P., \& Jack, S. (2008). Qualitative case study methodology: Study design and implementation for novice researchers. The Qualitative Report, 13(4), 544-559.

Butcher, S., \& Wilton, R. (2008). Stuck in transition? Exploring the spaces of employment training for youth in intellectual disability. Geoforum, 38, 1079-1092.

Collet-Klingenberg, L. L., \& Kolb, S. M. (2011). Secondary and transition programming for 18-21 year old students in rural Wisconsin. Rural Special Education Quarterly, 30(2), 19-27.

Lindstrom, L., Doren, B., \& Miesch, J. (2011). Waging a living: Career development and long-term employment outcomes for young adults with disabilities. Exceptional Children, 77(4), 423-434.

Oertle, K. M., \& Trach, J. S. (2007). Interagency collaboration: The importance of rehabilitation professionals' involvement in transition. Journal of Rehabilitation, 73(3), 36-44.

Pinkney, C. J., Murray, C. J., \& Lind, J. R. (2012). Individual skill predictors of the school- and career-related adjustment of adolescents with disabilities. Career Development and Transition for Exceptional Individuals, $35(1), 39-49$.

Shogren, K. A., \& Plotner, A. J. (2012). Transition planning for students with intellectual disability, autism, or other disabilities: Data the national longitudinal transition study-2. Intellectual and Development Disabilities, 50(1), 16-30. http://dx.doi.org/10.1352/1934-9556-50.1.16

Thomas, S. B., \& Dykes, F. (2011). Promoting successful transitions: What can we learn from RTI to enhance outcomes for all students? Preventing School Failure, 55(1), 1-9.

\section{Copyrights}

Copyright for this article is retained by the author(s), with first publication rights granted to the journal.

This is an open-access article distributed under the terms and conditions of the Creative Commons Attribution license (http://creativecommons.org/licenses/by/3.0/). 